\title{
A CIDADE, $O$ IMPERADOR E OS SENTIDOS DA MEMÓRIA:

\author{
o governo de Valente em Antioquia \\ (371-378)
}

The city, the emperor and the meanings of memory:

the government of Valens in Antioch (371-378 AD)

\section{RESUMO}

Antioquia, a metrópole da província da Síria Coele e uma das maiores cidades do Império Romano, foi, na época tardia, residência oficial de diversos imperadores, a exemplo de Diocleciano, Constâncio II, Galo, Juliano e Valente. Em alguns casos, a relação do imperador com a população se revelou abertamente conflituosa, em outros, no entanto, prevaleceu a concórdia. Seja como for, cada soberano buscou, ao seu modo, imprimir, na cidade, uma marca do seu governo, como uma estratégia de preservação da memória, razão pela qual Antioquia sempre foi objeto da generosidade edilícia dos imperadores. Neste artigo, pretendemos revisitar o episódio da passagem de Valente por Antioquia, que se encontra profundamente condicionado pela imagem negativa elaborada por Amiano Marcelino e pelos autores das histórias eclesiásticas do século V (Sócrates, Sozomeno e Teodoreto de Ciro) devido à perseguição contra os praticantes das artes mágicas e contra os adeptos do credo de Niceia deflagrada pelo Estado imperial. Não obstante os relatos que tendem a desqualificar o governo de Valente em Antioquia, importa reconhecer que o imperador foi o responsável pela construção de um fórum que logo se torna um dos pontos focais da paisagem urbana, o que revela o seu apreço pela cidade. Desse modo, é necessário relativizar o discurso de Amiano Marcelino e dos cronistas eclesiásticos segundo o qual Valente teria sido um soberano inclemente, irascível e, portanto, malquisto pela população de Antioquia.

Palavras-chave: Antiguidade Tardia, Antioquia, Valente, Cidade. Memória.
Gilvan Ventura da SILVA

(D) gil-ventura@uol.com.br

Universidade Federal

do Espírito Santo,

Vitória, ES, Brasil

\begin{abstract}
Antioch, the metropolis of the province of the Syria Coele, was one of the biggest towns in the Roman Empire, and, in the 4 th century $A D$, the residence of several emperors, such as Diocletian, Constantius II, Gallus, Julian and Valens. Sometimes the relationship between the emperor and the population was openly hostile, but in certain cases harmony prevailed. Truth to tell, every sovereign strived to leave, on the city, the mark of his government as a strategy adopted in order to preserve his memory. Therefore, Antioch was a city that could always count on the lavish generosity of the emperors. In this article, we intend to revisit the episode regarding the Valens' stay at Antioch. Such episode is deeply influenced by the negative image created by Ammianus Marcellinus and by the authors of the ecclesiastical histories (Socrates, Sozomenus and Theodoretus of Cyrus) due to the persecution against the practitioners of magic and the Nicene believers decreed by the Roman government. Notwithstanding such narratives, we should recognize that Valens was responsible for building a new forum in downtown Antioch which quickly became one of the focal spots of the urban landscape, what reveals the importance of the city to him. In our opinion, it is necessary to revaluate the Ammianus' and ecclesiastical historians' narratives that spread the image of Valens as an irascible and merciless emperor hated by the population of Antioch.
\end{abstract}

Keywords: Late Antiquity, Antioch, Valens, City, Memory. 
m termos historiográficos, o século IV costuma ser dominado por um seleto grupo de imperadores que compartilham a atenção tanto dos autores antigos quanto dos modernos, a começar por Diocleciano, cujo governo é tido como um autêntico turning point na história romana, não apenas por ter superado o risco iminente de fragmentação do Império, encerrando assim a Crise do Século III, mas também por lançar as bases de um novo sistema político - o Dominato -, o que exigiu a adoção de um extenso conjunto de reformas com o propósito de reforçar a autoridade do poder imperial e tornar mais eficiente a administração pública. ${ }^{1}$ Além de Diocleciano, Constantino, Juliano e Teodósio são imperadores que gozam igualmente de destaque, em boa parte devido à política religiosa que implementaram ou buscaram implementar, ao passo que outros ocupam uma posição claramente secundária, a exemplo de Valentiniano e seu filho, Graciano, cujos governos são, em geral, encarados com benevolência, mas sem despertar maior interesse. Um terceiro grupo seria constituído por imperadores anódinos, efêmeros e tidos como ineptos e que, por isso mesmo, são tratados de modo ligeiro e superficial, como vemos no caso de Constantino II, Constante, Joviano e Valentiniano II. ${ }^{2}$ Por fim, há aqueles que, a despeito do tempo de governo e do acerto de diversas decisões que tomaram, são considerados, ao fim e ao cabo, "maus" imperadores, o que explica - mas decerto não justifica - o estado de relativa indigência historiográfica no qual ainda se encontram. Fazem parte desta categoria Constâncio II e Valente que, além de sofrerem com os estereótipos e preconceitos contidos nas fontes antigas, não têm comparecido amiúde na agenda dos investigadores, com uma ou outra exceção. Quanto a isso, deve-se sem dúvida comemorar o aparecimento, em 2016, da primeira biografia de Constâncio II, elaborada por Peter Crawford, bem como a publicação, em 2002, do livro de Noel Lensky dedicado a Valente, o primeiro estudo de fôlego sobre o governo de um imperador que costuma ser lembrado não pela austeridade da sua gestão, mas pela fragorosa derrota sofrida diante dos godos, em 378, no episódio conhecido como "Desastre de Adrianópolis", quando o exército do Oriente foi praticamente destroçado, tendo na ocasião o soberano perecido de morte pouco honrosa, incinerado numa cabana na qual havia buscado refúgio.

Tanto no caso de Constâncio II quanto no de Valente, nos encontramos diante de lugares de memória poderosos o suficiente para obscurecer ou confundir nossa visão sobre este ou aquele imperador, sobre este ou aquele processo histórico, em parte devido ao protagonismo assumido por Amiano Marcelino e pelos autores das histórias eclesiásticas, que não raro promovem uma interpretação do passado conforme suas próprias convicções e interesses. A fim de confrontar estes relatos canônicos na tentativa de estabelecer uma avaliação menos parcial acerca dos imperadores da época tardia, é necessário deslocar o foco da discussão para outro nível, escapando dos assuntos que constituem o esteio desses relatos e que tendem a se impor como a principal matéria do passado. É um exercício como esse que desejamos realizar aqui, na medida em que pretendemos revisitar um episódio ocorrido entre 371 e 378 : a instalação de Valente em Antioquia, a metrópole da província da Síria Coele, que no século IV desponta como uma das maiores cidades do Mediterrâneo. Nossa intenção é demonstrar como a obra de Amiano Marcelino e as histórias eclesiásticas de Sócrates, 
Sozomeno e Teodoreto de Ciro foram responsáveis, cada qual ao seu modo, por criar uma memória de Valente como um soberano que teria imposto à cidade inúmeros contratempos ao infundir medo e terror na população. Tais narrativas, no entanto, silenciam a respeito da ampla intervenção feita pelo imperador no centro urbano logo ao se instalar na cidade e que culminou na criação do fórum que leva seu nome, a última grande reforma executada em Antioquia, no século IV, com recursos do poder central. Destinado a sobreviver ao desaparecimento do seu fundador, o Fórum de Valente pode ser a justo título considerado um testemunho de outra face do soberano praticamente ignorada pela maioria dos autores da época tardia: a de um notável evergeta que, ao eleger Antioquia como capital em detrimento de Constantinopla, desejou legar à posteridade um monumento à grandeza da majestade imperial, o que sem dúvida constituiria motivo de orgulho para os habitantes. Mediante a reflexão sobre a importância da construção de um novo fórum em Antioquia, é possível realizar um contraponto à imagem de Valente como a de um imperador cruel e irresponsável que, segundo a perspectiva, teria levado à ruína muitas casas ilustres ou semeado a discórdia na congregação cristã, já cindida em diversas facções desde os tempos de Constantino.

\section{Dois irmãos, um governo}

Valente era o irmão mais novo de Valentiniano, imperador proclamado pelas tropas, em Niceia, em 25 de fevereiro de 364, cerca de dez dias após o súbito falecimento de Joviano, no caminho de Constantinopla. Valentiniano, um militar de carreira nascido em Cibale, na Panônia, havia sido recentemente promovido por Joviano ao cargo de comandante da segunda divisão dos scutarii, que se encontrava então aquartelada em Ancira, o que justifica o atraso na sua elevação à púrpura, procedimento pouco convencional, diga-se de passagem (CURRAN, 2008, p. 81). Apresentando-se diante do exército, o novo imperador pronuncia a sua adlocutio, o discurso oficial de investidura no cargo, ocasião em que se costumava anunciar um donativo de ouro e prata ao exército a fim de selar sua lealdade para com o regime que então se iniciava. Contudo, tão logo toma a palavra, Valentiniano é interrompido pelos legionários, que exigem a proclamação de um segundo regente, procedimento que havia se tornado rotineiro desde a época de Diocleciano e que, na opinião de Hughes (2013, p. 19), deve ser interpretado não apenas como um expediente visando a otimizar a administração do Império, cada dia mais complexa, mas também a salvaguardar os postos de trabalho da chancelaria, que certamente seriam reduzidos com a fusão das cortes oriental e ocidental. Além disso, havia o permanente conflito com a Pérsia Sassânida, o que exigia uma presença militar consistente no front oriental de modo a salvaguardar as possessões romanas ameaçadas pela ofensiva persa. Surpreso com a solicitação, Valentiniano pede às tropas um pouco de paciência, pois o escolhido deveria ser alguém de sua confiança, no que é atendido. Cerca de um mês depois, em 28 de março, proclama seu irmão, Valente, como Augustus, numa rápida cerimônia que teve lugar perante os destacamentos reunidos no Campus Tribunalis, nos arredores de Constantinopla. Antes dessa data, em $1^{\circ}$ de março, Valentiniano já havia dado sinais de que a escolha recairia sobre Valente ao nomeá-lo tribunus stabuli com a 
responsabilidade de supervisionar a aquisição e manutenção dos cavalos de guerra (HUGHES, 2013, p. 21).

Sete anos mais novo que Valentiniano, Valente era também nativo de Cibale, tendo nascido em meados de 328. No entanto, ao contrário do irmão e do pai, Graciano, ${ }^{3}$ não era considerado apto para o serviço militar devido às pernas tortas, ao excesso de peso e à visão deficiente, talvez em consequência de uma catarata. Sem muito futuro no exército, Valente foi encarregado pelo pai de supervisionar as propriedades da família, recebendo assim treinamento em administração, conhecimento que mais tarde, ao se tornar imperador, revelar-se-ia bastante útil. Ainda na condição de civil, contrai matrimônio com Domnica, filha de Petrônio, muito provavelmente um militar que fazia parte do círculo de amizades de Graciano. Não obstante as limitações físicas e a opção pela vida civil, Valente não poderia evitar ad infinitum o engajamento nas forças armadas, uma vez que, em meados do século IV, um dos maiores desafios do Império em termos estratégicos era justamente solucionar a crônica falta de combatentes, o que o levou a ser convocado em 359, quando Constâncio II decidiu lançar um ambicioso programa de recrutamento, tendo em vista a ofensiva que pretendia deflagrar contra a Pérsia. Ao que parece, Graciano, valendo-se de sua rede de contatos, foi capaz de assegurar para o filho uma posição como protector domestici que, à época, representava o nível mais baixo do oficialato, seguido pelas patentes de tribunus e de comes. Considerando que um simples miles somente estaria apto a assumir o posto de protector após vinte anos de caserna e que mesmo para um soldado razoavelmente instruído tornar-se protector exigia alguma experiência como burocrata a serviço dos comandos militares (BABUT, 1913, p. 225 e ss.), o fato de Valente ter sido prontamente alçado à posição de oficial é um indício revelador do grau de influência de seu pai junto aos estratos dirigentes do Império. Após a morte de Constâncio, em novembro de 361, Valente continuou a servir como protector domestici até 362, quando a schola dos protectores foi drasticamente reduzida por Juliano, que o transferiu para uma unidade subalterna aquartelada em Sírmio. É provável que a demissão de Valente tenha sido um dano colateral provocado pela recusa de Valentiniano, um oficial graduado, a renunciar à fé cristã sob um governo cuja proposta, em termos religiosos, era reabilitar os cultos pagãos.

Quando Valentiniano foi proclamado imperador, tudo indica que Valente se encontrasse nos arredores de Nicomédia, aguardando a chegada da comitiva imperial proveniente de Niceia. Daí os irmãos seguiram para Constantinopla, onde Valente foi proclamado Augusto, conforme mencionamos. Logo após, ambos os imperadores foram acometidos de uma súbita moléstia, acontecimento interpretado como consequência do uso de feitiçaria pelos seus adversários, o que deu ensejo a um inquérito sobre o assunto, mas sem que nada de conclusivo fosse apurado. Em seguida, na assim denominada "Conferência de Naisso", os irmãos repartem formalmente os efetivos militares e as prefeituras do pretório. Em agosto de 364, em Sírmio, procedem às despedidas solenes. Doravante Valentiniano passaria a residir em Mediolanum (Milão), ao passo que Valente se dirige a Constantinopla, onde tem de lidar com a tentativa de usurpação de Procópio, um parente da mãe de Juliano, Basilina, que havia exercido um comando militar durante a campanha da Pérsia, na qual o imperador veio a falecer 
(CURRAN, 2008, p. 82). Vencido o usurpador, em maio de 366, Valente decide fixar residência em Constantinopla, aí permanecendo até 371, período no qual ocupa-se em garantir o domínio romano sobre a Armênia e a Ibéria, ameaçado pelas pretensões expansionistas de Sapor, o soberano persa. Nesse ínterim, passa uma temporada em Marcianópolis, na Trácia, por conta de uma incursão dos godos, situação contornada mediante um acordo de paz celebrado em 369. Após algumas idas e vindas pelas províncias do Oriente com o propósito de defender o território contra as investidas de godos e persas, Valente começa os preparativos para se instalar em Antioquia, como nos permite concluir uma lei de outubro de 370 endereçada ao comes rei privatae Fortunatiano na qual o imperador determina a liberação do aqueduto responsável por abastecer o palácio imperial de Dafne, cujas águas haviam sido desviadas por particulares, uma vez que o edifício encontrava-se inativo desde pelo menos março de 363 , quando Juliano deixa a cidade para dar combate aos persas (C. Th., 15, 2, 2).

\section{Crime e punição na nova capital}

Segundo o registro de João Malalas (Chron. 13, 29), um cronógrafo do século $\mathrm{VI}$, o adventus de Valente em Antioquia ocorreu em 10 de novembro de 371, no contexto da assinatura de uma trégua de sete anos com a Pérsia. A chegada do imperador, no entanto, não trouxe uma temporada de calmaria para os antioquenos, pois no final do ano a cidade é abalada pela denúncia de uma grave conspiração. De acordo com Amiano Marcelino (XXIX, 5, 10), nossa melhor testemunha acerca do ocorrido, dois oficiais do tesouro, Anatólio e Espudásio, haviam sido acusados de desvio de dinheiro por certo Procópio e seu superior, o comes rei privatae Fortunatiano, que aproveitam a oportunidade para implicar Anatólio e Espudásio num delito ainda mais grave: o de veneficium, ou seja, crime de magia. Pelo que foi possível apurar no decorrer da investigação, os acusados teriam contratado um veneficus (feiticeiro) conhecido como Paládio e um astrólogo de nome Heliodoro para assassinar Fortunatiano. Na medida em que, em meados do século IV, a acusação de veneficium era considerada da mais alta gravidade, sendo equiparada ao delito de maiestas, isto é, a um atentado contra a pessoa sagrada do imperador (SILVA, 2003, p. 233 e ss.), o caso foi entregue aos cuidados de Modesto, o prefeito do pretório do Oriente, numa conjuntura em que, no Ocidente, Valentiniano, sob o pretexto de coibir o uso da magia com propósitos maléficos, realizava uma devassa entre os membros da elite senatorial. ${ }^{4}$ No interrogatório diante do prefeito do pretório, Paládio não se limitou a responder às perguntas sobre a tentativa de homicídio contra Fortunatiano, mas foi além, declarando ter conhecimento de um complô contra Valente urdido por Fidústio, um antigo governador de província, e por Hilário e Patrício, homens instruídos nas artes divinatórias. Conforme o depoimento de Paládio, os três acusados teriam se reunido para consultar as potestades sobrenaturais acerca da sucessão imperial por meio de um tabuleiro mágico contendo as 24 letras do alfabeto grego. Sobre o tabuleiro havia um anel suspenso por um fio de linho que oscilava de modo a soletrar a resposta à pergunta do consulente. Após recitar um encantamento próprio para a ocasião, o oficiante da cerimônia indagou qual seria o nome do próximo imperador. As quatro primeiras letras indicadas pelo anel foram teta, épsilon, ômega e delta, ou 
seja, THEOD (Am. XXIX, 1, 29-32). Mesmo inconcluso, o presságio foi interpretado como se referindo a Teodoro, um notário gaulês que teria acompanhado Juliano ao Oriente, em 361. Teodoro, que não estava presente à sessão, foi um pouco depois informado por Eusério, o vicário da Ásia, acerca do seu futuro iminente.

Tão logo tomou ciência do acontecido, Valente, num acesso de cólera, determinou a instalação de um tribunal sob a presidência de Modesto para julgar o caso. Antioquia, a sede do tribunal, se viu de um momento para o outro envolvida num inquérito de amplas proporções, pois os acusados eram trazidos aos borbotões de diversas províncias do Oriente para serem julgados na cidade. Teodoro, ele mesmo, foi convocado às pressas de Constantinopla, onde se encontrava a serviço, para prestar esclarecimentos. Segundo Amiano (XXIX, 1, 12), em Antioquia os julgamentos eram realizados dia e noite. Em virtude da quantidade de pessoas denunciadas, nem os cárceres públicos ou as residências privadas tinham condições de acomodá-las (Am. XXIX, 1, 12-13), optando-se por mantê-las ao ar livre, em grupos unidos por correntes de ferro, o que certamente proporcionava um triste espetáculo. A cidade foi então tomada pelos lamentos dos réus, conduzidos em grilhões à presença do prefeito do pretório (Am. XXIX, 1, 23), o que deixou uma vívida impressão em Amiano, para quem Valente teria se excedido ao perseguir culpados e inocentes, de modo que "alguns tomavam ciência de terem sido condenados à morte antes mesmo de saberem que estavam sob suspeita" (Am. XXIX, 1, 18). O autor, ao relatar a participação do imperador no julgamento, o compara a uma besta sanguinária adestrada para combater nas venationes (Am. XXIX, 1, 27).

Muito embora a atuação de Valente contra os acusados de veneficium não deva ser interpretada como um desejo de coibir o paganismo e seus adeptos, como corretamente assinalam Noel Lensky (2002, p. 218) e Gavin Kelly (2018, p. 156), não resta dúvida que o incidente, da maneira como é narrado por Amiano, contribuiu para a construção de uma imagem do imperador calcada na intolerância, na falta de moderação e na cobiça desenfreada, em especial contra os réus mais ricos, que poderiam ser livremente espoliados em benefício do Erário. Desse modo, a passagem de Valente por Antioquia teria sido marcada por uma atmosfera de aguda tensão e mesmo por certo obscurantismo, como demonstram as inúmeras apreensões de livros sob a suspeita de conterem fórmula mágicas. De posse das autoridades, os livros eram prontamente lançados à fogueira, ainda que muitos deles, como esclarece Amiano (XXIX, 1, 41), tratassem apenas de lições escolares ou de assuntos jurídicos. Ao que tudo indica, a atuação arbitrária de Valente em Antioquia gerou profunda insatisfação entre os habitantes, que costumavam protestar desejando que o imperador fosse vitimado pelo fogo, fato que Amiano $(X X X I, 1,2)$ interpreta como um presságio da morte que mais tarde Valente sofreria nas mãos dos godos. É possível que, como relata o autor na mesma passagem, a multidão em revolta tenha ateado fogo ao edifício conhecido como Termas de Valente. Se o incêndio de fato ocorreu, ele deve ser situado após a morte do imperador, pois não temos notícia de nenhum motim ou mesmo de qualquer ato de repressão contra os antioquenos durante o tempo em que Valente residiu na cidade. Seja como for, um ato dessa natureza constitui uma importante evidência do grau de desgaste nas relações entre o soberano e a população. 


\section{Melécio e a resistência nicena}

Deixando de lado a narrativa de Amiano Marcelino sobre a atuação de Valente em Antioquia, vejamos agora a maneira como o imperador se relacionava com os cristãos da cidade, o que nos permite capturar os contornos de outra imagem construída acerca do seu governo pelos autores eclesiásticos. Assim como no caso de Amiano, o tratamento dispensado a Valente por Sócrates, Sozomeno e Teodoreto de Ciro é amplamente desfavorável, uma vez que o imperador é acusado de causar distúrbio entre os cristãos de Antioquia ao perseguir a comunidade nicena liderada por Melécio, que há décadas vivia em conflito com os arianos. À época do concílio de Niceia, em 325, Eustácio, o bispo local, havia se alinhado aos adversários do arianismo, polemizando com Eusébio de Cesareia, o que Ihe valeu a condenação num concílio reunido em Antioquia por volta de 327 e presidido pelo próprio Eusébio. Eustácio é então deposto sob a acusação de sabelianismo e enviado em exílio para Trajanópolis, ${ }^{5}$ na Trácia, onde permanece até a morte, em data desconhecida (CROSS; LIVINGSTONE, 2005, p. 579). Após sua deposição, vários bispos adeptos de um arianismo moderado respondem pela sé da cidade até que em 358, devido ao falecimento de Leôncio, Eudóxio de Germanícia, um ariano de tendências radicais, é bem-sucedido em eleger-se bispo de Antioquia, cargo que ocupa por um curto período. Confrontado pela reação dos arianos moderados, Eudóxio termina por capitular, assumindo assim uma posição menos intransigente quanto à natureza de Cristo, recuo que Ihe valeu a reabilitação junto à corte de Constâncio II, que autoriza sua transferência para Constantinopla a fim de substituir Macedônio, deposto em 360 (BERARDINO, 2002, p. 531).

Para o bispado de Antioquia, então vacante devido à transferência de Eudóxio, é eleito Melécio, bispo de Sebaste, na Armênia, um prelado de inclinação homeousiana. ${ }^{6}$ A eleição de Melécio não havia sido bem recebida pela congregação de Sebaste, fiel ao antigo bispo, Eustácio, destituído por maquinações de seus inimigos, o que fez Melécio em pouco tempo renunciar ao cargo. Após retirar-se para Bereia e participar do Concílio de Selêucia, em 359, Melécio foi ordenado bispo de Antioquia pelas mãos de Acácio de Cesareia, que gozava de grande prestígio nos meios eclesiásticos do Oriente. No entanto, alguns meses após ser investido da dignidade episcopal, numa homilia pronunciada na presença de Constâncio II, propõe uma interpretação francamente antiariana da divindade de Cristo, o que resulta na sua imediata deposição e consequente exílio para a Armênia (KELLY, 1995, p. 12). Em seu lugar, assume Euzoio, um antigo aliado de Ário desde os tempos de Alexandria. Diodoro e Flaviano, membros ativos da entourage de Melécio, rompem a comunhão com o novo bispo e passam a reunir a congregação de modo independente. Após a morte de Constâncio, em novembro de 361, Juliano autoriza o retorno às suas respectivas sés de todos os bispos outrora exilados (Am. XXII, 5, 3-4), quando então Melécio retoma o controle da sua assembleia, colocando-se em oposição não apenas a Euzoio, o bispo ariano, mas também a Paulino, que por volta de 350 havia se tornado o líder de um dos ramos dos nicenos de Antioquia. A despeito da adesão de Melécio ao credo de Niceia logo no início do seu episcopado, Paulino, que se declarava fiel a Eustácio, o bispo deposto em 327, continuou a liderar o contingente de nicenos que não reconheciam a autoridade de Melécio. A situação se torna ainda mais confusa em 362, quando 
Lúcifer de Cagliaris, apoiado por Libério de Roma, ordena Paulino como bispo, ato reconhecido por Atanásio de Alexandria (DOWNEY, 1961, p. 397). Desse modo, quando da ascensão de Juliano, os cristãos de Antioquia se encontravam repartidos em três facções: duas nicenas e uma ariana. Aos poucos, no entanto, os melecianos se apoderam das igrejas da cidade, a começar pela Palaia, a mais antiga. Em seguida, sob Joviano, ocupam a Domus Aurea, a majestosa basílica octogonal erguida na ilha do Orontes por Constantino e Constâncio (SOLER, 2006, p. 145).

Tudo levava a crer que Melécio conseguiria se consolidar como único bispo de Antioquia, não fossem as medidas adotadas contra os nicenos por Valente. Ao contrário de seu irmão, Valentiniano, que se absteve de maior envolvimento nos assuntos internos da Igreja durante o tempo em que governou o Ocidente, limitando-se a coibir a atuação dos maniqueus e a proibir o rebatismo pelos donatistas, Valente, responsável por um território marcado pela cizânia entre o episcopado, não tardou a favorecer os arianos, o que o levou, em certa medida, a seguir os passos de Constâncio II ao referendar os credos estabelecidos nos concílios de Ariminum, Selêucia e Constantinopla (JONES, 1964, p. 150). Pretendendo restituir o status quo vigente à época de Constâncio, Valente promulga, em 5 de maio de 365, um edito enviando novamente ao exílio os bispos que haviam retornado às suas sés por decisão de Juliano, dentre os quais conta-se Melécio. Nesse ínterim, Euzoio é alçado uma vez mais à posição de bispo "oficial" da cidade, ao passo que Paulino, não incluído no edito de Valente, se mantém à frente de sua assembleia (DOWNEY, 1961, p. 411). Supõe-se que devido a uma conjuntura de instabilidade provocada pela campanha de Valente contra os godos, Melécio tenha logrado burlar a vigilância imperial, retornando assim a Antioquia, onde permanece até 370 ou 371, quando o recrudescimento da perseguição aos nicenos o obriga novamente a se exilar. Capitaneados uma vez mais por Diodoro e Flaviano, os melecianos passam a se reunir nas grutas aos pés do Monte Sílpios, às margens do Orontes e no Ginásio Militar (o equivalente ao Campo de Marte), diante da Porta do Norte (SOLER, 2006, p. 145). A intervenção de Valente nas igrejas do Oriente tem um impacto direto sobre a congregação antioquena, enfraquecendo a posição de Melécio, a principal autoridade religiosa local, e contribuindo para aprofundar o cisma que há anos dividia os cristãos. ${ }^{7}$ Por essa razão é que os historiadores eclesiásticos do século $\mathrm{V}$, ao narrarem as peripécias de Melécio e dos nicenos de Antioquia, não hesitam em classificar Valente como um rude perseguidor, o que justificaria a morte indigna que sofreu nas mãos dos godos, tidos como instrumentos da ira divina.

Segundo o relato de Sócrates (IV, XVII), Valente, no decorrer da sua estada em Antioquia, expulsou da Igreja muitos daqueles que defendiam o homoousios, fustigandoos com severas punições, incluindo a morte por afogamento no Orontes. Sozomeno (VI, VII), que publica sua História Eclesiástica alguns anos depois de Sócrates, recorda que Valente não apenas perseguiu Melécio, como também todos aqueles que não se encontravam em comunhão com Euzoio, destituindo-os sumariamente de suas igrejas. Apenas Paulino teria sido poupado, em virtude da admiração do imperador, que o considerava um homem santo. É possível que o prestígio de Paulino como asceta o tenha favorecido nesse caso, mas não podemos ignorar o fato de que a comunidade por ele liderada era, ao que tudo indica, muito menor que a de Melécio, de maneira 
que os paulinistas não representavam uma ameaça à hegemonia de Euzoio, o que certamente contribuiu para que não sofressem represálias por ocasião das medidas adotadas contra os nicenos. ${ }^{8}$ Além disso, tendo sido ordenado em 362, após a morte de Constâncio, Paulino não estaria incluído no decreto por meio do qual Valente suspendia a anistia concedida aos bispos nicenos por Juliano.

Após a expulsão de Melécio, Diodoro e Flaviano, como dissemos, assumem a tarefa de organizar a resistência dos melecianos, no que recebem a colaboração de Afraate, um influente asceta sírio, e de outro monge, Juliano Sabas. Nativo da Pérsia, Afraate havia se convertido, na juventude, ao cristianismo, o que o levou a deixar seu país de origem para se instalar em Edessa, cidade do norte da Mesopotâmia que abrigava uma comunidade cristã florescente, vivendo em reclusão nas cercanias da cidade até fixar residência em Antioquia no final do governo de Constâncio II, ou seja, em 360 ou 361 (FESTUGIÈRE, 1959, p. 274). Reputado como um notável théos áner, isto é, um homem divino, Afraate decide abraçar a causa dos melecianos, passando a colaborar ativamente com Flaviano e Diodoro após o afastamento de Melécio. Segundo Teodoreto de Ciro (Hist. Eccl. IV, XXXIII), certo dia, quando o monge passava pela ilha do Orontes a caminho do Ginásio Militar, onde costumava celebrar o serviço litúrgico, teria sido abordado por Valente, que o indagou para onde se dirigia. Prontamente, Afraate responde: “Orar pelo seu império”. Contrariado com a resposta, o imperador o aconselha a voltar para casa e rezar sozinho, como faziam os monges. Sem se intimidar, Afraate declara: "Você incendiou a casa de nosso Pai e eu estou fazendo o possível para extinguir o fogo". Ainda insatisfeito, Valente o ameaça, mas o deixa prosseguir. No entanto, um dos seus camareiros desacata o monge, pagando em seguida um alto preço pela insolência. Encarregado de preparar o banho do imperador, o camareiro se desequilibra e cai na banheira de água fervente, vindo assim a óbito. De acordo com Teodoreto, muito embora Valente tenha reconhecido, nesta fatalidade, uma demonstração da dynamis de Afraates, manteve, tal como o faraó, o coração empedernido, não se dobrando à vontade divina. Como assinala Festugière (1959, p. 274), a narrativa decerto pertence ao ciclo de anedotas sobre Afraate que circulavam em Antioquia, sendo impossível atestar a veracidade do encontro com o imperador. ${ }^{9}$ De qualquer modo, o mais importante é constatar a função que o relato desempenha ao ser recolhido por Teodoreto: a de reforçar a imagem de Valente como um perseguidor da Igreja, o que o leva a desafiar até mesmo os homens divinos, que têm como principal incumbência salvaguardar a integridade da fé, ou seja, o credo niceno.

Função semelhante é aquela desempenhada pelo relato da atuação de Juliano Sabas, um arameu de Osroene, cidade situada na fronteira entre a Síria e a Mesopotâmia, que havia fundado inúmeros mosteiros em seu país (FESTUGIÈRE, 1959, p. 247). Ao contrário de Afraate, que residia em Antioquia desde os tempos de Constâncio, Juliano se dirigiu à cidade apenas em 365, quando do segundo exílio de Melécio, a fim de dar apoio aos partidários do bispo deposto. Em virtude do prestígio de homem divino do qual desfrutava, os arianos se empenhavam em difundir o boato segundo o qual Juliano havia rejeitado o símbolo de Niceia em favor do arianismo, razão pela qual Diodoro e Flaviano se apressaram em enviar dois emissários, Acácio e Astério, 
para convencer o monge a deixar o deserto e fixar residência em Antioquia, onde executou inúmeros milagres que, de acordo com Teodoreto (Hist. Eccl. IV, XXIV), foram responsáveis por atrair muitos adeptos para o rebanho dos melecianos. Os milagres realizados por Juliano Sabas em Antioquia são narrados pelo autor em História Religiosa ou Histórias dos monges da Síria, obra escrita por volta de 444. Num dos momentos mais emblemáticos da carreira de Juliano como taumaturgo, um paralítico é curado ao tocar as vestes do monge, que passava diante do palácio imperial. Segundo Teodoreto (Hist. relig., 2, 18), "após esta ação, afluiu todo o povo da cidade e o Ginásio Militar [onde as tropas se exercitavam] ficou repleto com tantas pessoas que ali acorreram. Os sicofantas e os especialistas na mentira [i. é, os arianos] ficaram envergonhados, enquanto aqueles nutridos na fé [i. é, os nicenos] se encheram de júbilo e alegria”. A narrativa tem o mérito de revelar todo o apelo simbólico contido na atuação de Juliano Sabas, que por meio de seus milagres buscava minar a comunidade dos arianos e ao mesmo tempo fortalecer a posição de Melécio e seus seguidores.

Muito embora tenhamos conhecimento de que em 377, pressionado pelas investidas dos godos na Trácia, pelo caráter impopular da sua política religiosa e pela resistência dos monges, aguerridos defensores do credo de Niceia, Valente tenha proclamado um edito autorizando o retorno às suas respectivas sés de todos os bispos nicenos por ele exilados (SNEE, 1985, p. 413 e 22.), incluindo Melécio, tal decisão não é mencionada por Sócrates, Sozomeno ou Teodoreto de Ciro, o que não deve nos causar estranheza, em face do comprometimento destes autores com a construção da imagem de Valente como um perseguidor da Igreja que havia recebido de Deus a justa punição pelas atrocidades cometidas, conforme assinalamos. Esta lição sobre a intervenção da Providência divina contra o imperador é transmitida sem rodeios por Sozomeno (VI, $\mathrm{XL}$ ), que forja um diálogo entre Isaque, o fundador do monacato constantinopolitano, e Valente ocorrido no momento em que este partia para a Trácia, onde combateria os godos. Apresentando-se diante do soberano, Isaque o exorta a restituir as igrejas aos nicenos a fim de obter a vitória. Irritado, Valente ordena a detenção de Isaque até o seu retorno, quando então o levaria a julgamento. Numa clara demonstração de parrhesia, de liberdade de expressão, o monge faz a seguinte profecia: "você não voltará a menos que restitua as igrejas [aos nicenos]". O mesmo acontecimento é descrito por Teodoreto (Hist. Eccl. IV, XXVI-XXVII), embora com mais detalhes, uma vez que Isaque teria declarado a Valente que a revolta dos godos contra o Império havia sido determinada por Deus, descontente com a difusão da blasfêmia dentro da Igreja. Diante da recusa do imperador em rever seu procedimento, não restava à Providência outra alternativa senão fazê-lo pagar por seus erros, conduzindo-o a uma morte excruciante, como sói ocorrer com os perseguidores. Queimado vivo numa cabana, Valente enfim expiava seus crimes, passando para a história como mais um dos que tiveram um fim lamentável por ousarem confrontar a "verdadeira" fé. Desse modo, os historiadores eclesiásticos, assim como Amiano Marcelino, contribuíram para disseminar uma imagem hostil acerca de Valente, um soberano cuja memória passa a ser então associada à crueldade, à intolerância e à impiedade, o que o teria tornado persona non grata para os habitantes de Antioquia entre 371 e 378 , anos em que aí residiu. 


\section{Antioquia, emblema da glória imperial}

A imagem de Valente como um soberano impopular e malquisto pelos antioquenos não é, seguramente, a única capaz de exprimir a natureza das relações mantidas pelo imperador com Antioquia. Se é verdade que os julgamentos de veneficium e maiestas presididos por Modesto e a perseguição a Melécio e seus correligionários deixaram marcas profundas no tecido social da cidade, colocando em posição embaraçosa tanto os membros da aristocracia quanto os segmentos médios e mesmo os mais humildes, não é menos verdade que Valente buscou também se notabilizar como um benfeitor da pólis, sem dúvida com o propósito de estreitar os laços que o uniam à população. Para tanto, uma das principais estratégias que empregou foi o patrocínio de construções no perímetro urbano cuja função era, por um lado, exaltar a majestade imperial e, por outro, conferir maior brilho à cidade, com a previsível elevação da autoestima dos habitantes, que nutriam por Antioquia uma autêntica devoção, como nos revela Libânio no seu Antiochikos, um extenso panegírico pronunciado por ocasião dos Jogos Olímpicos de 356. Desde Augusto, a atividade edilícia sempre constituiu um eficaz instrumento visando tanto a garantir a lealdade dos súditos quanto a realçar a autoridade do imperador, o que não foi negligenciado, em absoluto, por Valentiniano e Valente, tidos como notórios evergetas responsáveis pela execução de obras públicas em toda a extensão do orbis romanorum, com destaque para aquelas que poderiam beneficiar um maior contingente, a exemplo de aquedutos, termas e pontes, predileção que, segundo Lensky (2002, p. 393-394), se deve ao pragmatismo que caracterizou a gestão de ambos os imperadores, sempre preocupados em facilitar o dia a dia das pessoas comuns. Mesmo um autor bastante crítico quanto à atuação de Valente, como Amiano Marcelino $(X X X I, 14,4)$, não deixa de descrevê-lo como um notável construtor, eximindo-se, todavia, de reportar suas realizações a fim de não parecer prolixo, justificativa elegante para não reconhecer os méritos do soberano nesse domínio. Uma singular evidência do interesse do imperador por ornar as cidades com construções nos é transmitida por Temístio de Bizâncio em sua Oratio 11, um encômio em homenagem aos dez anos de governo de Valente pronunciado em 373. Segundo Temístio (Or. 11, 12), assim como o Sol ilumina e aquece tanto os corpos animados quanto os inanimados, Valente impulsiona as cidades grandes e pequenas de modo indistinto, acentuando em umas a beleza e em outras a grandeza, de maneira que a "cada cidade é dado algo de novo ou se acresce algo àquilo que já possuía", ao mesmo tempo que são recuperadas as cidades atingidas pelas calamidades (terremotos, inundações, crises de abastecimento). Desse modo, tanto Amiano quanto Temístio reconhecem o apreço do imperador pelas atividades edilícias, fato corroborado pelo registro epigráfico (LENSKY, 2002, p. 396-401).

Em Antioquia, Valente reparou o aqueduto de Dafne que servia ao palácio imperial, ergueu uma basílica próxima ao Kommodion (as Termas de Cômodo) e converteu o anfiteatro num kinegion, ou seja, num edifício adaptado aos espetáculos de caça (venationes) (LENSKY, 2002, p. 400; PETIT, 1955, p. 315-316). Sua principal iniciativa, no entanto, foi a inauguração de um novo fórum próximo ao Nymphaeum, a fonte das ninfas, na confluência da avenida das colunatas que conduzia à ilha do Orontes. Ao contrário das demais construções, não se tratava de erguer ou remodelar um 
elemento arquitetônico tomado na sua singularidade, mas de reorganizar todo o centro da ásty, motivo pelo qual o Fórum de Valente representou à época uma obra de grande envergadura, ocupando talvez uma área superior aos fóruns de Roma e Constantinopla, o que exprimia o desejo do imperador em situar sua nova residência num patamar equivalente ao das outras duas capitais (BRANDS, 2018, p. 22). A reforma, ao que parece, foi igualmente favorecida pelo terremoto de 365, que teria danificado a região central da cidade (DOWNEY, 1961, p. 400). Não sabemos ao certo quando as obras tiveram início, se logo após 365 ou a partir de 370, quando Valente manifesta a intenção de fazer de Antioquia sua capital. Em todo caso, os trabalhos foram concluídos antes de novembro de 375 , data da morte de Valentiniano, pois o fórum continha três estátuas do imperador, sendo improvável que uma homenagem como essa tenha sido prestada in memoriam. Embora as escavações lideradas pela Universidade de Princeton entre 1932 e 1939 não tenham sido bem-sucedidas em localizar a área do fórum, João Malalas $(13,30)$ nos legou uma descrição detalhada do complexo.

O Fórum de Valente foi erguido numa região ocupada desde os tempos helenísticos por uma praça repleta de construções. As mais antigas eram o Templo de Ares e o Templo de Atená, ambos datados da época helenística. Em seguida, havia o Kaisarion, uma ampla basílica edificada por Júlio César após a vitória sobre Pompeu, em 48 a.C., que abrigava as estátuas do ditador e da Tyché de Roma. Nas imediações, Trajano construiu a Porta Média, um arco monumental. Mais tarde, sob Cômodo, a praça recebeu o Kommodion e o Xistós, uma pista coberta para as corridas que faziam parte do programa dos Jogos Olímpicos. Um pouco depois Dídio Juliano ergueu o Plethrion, edifício destinado às disputas de pugilato. A praça também abrigava o Horologion, o relógio solar, cuja posição exata não é conhecida, mas devido à sua importância Downey (1961, p. 406) supõe que o monumento fosse bastante visível. Como podemos concluir, antes mesmo da intervenção de Valente a região já se destacava na paisagem urbana, embora a construção do novo fórum tenha exigido uma reforma completa, a começar pela ampliação da área de circulação, o que foi obtido mediante a pavimentação de um trecho do Parmênio e a demolição de parte do Kaisarion. A êxedra do Kaisarion, ${ }^{10}$ no entanto, foi restaurada e incorporada ao novo complexo. A área aberta do fórum era ladeada por quatro pórticos sustentados por colunas de mármore e decorados com pinturas, mosaicos e estátuas. Nos trabalhos de reconstrução, tanto o Plethrion quanto o Xistós e o Kommodion foram preservados. No lado oposto ao Kommodion e ao Xistós, Valente ergueu a nova basílica à qual aludimos. Três estátuas de Valentiniano foram colocadas no fórum, uma delas em posição central e as outras duas próximas à êxedra do Kaisarion. Nas cercanias, talvez no local do antigo Templo de Ares, o imperador fez instalar um macellum, ou seja, um mercado de víveres. Downey (1961, p. 404) acredita que as características do Templo de Ares, que dispunha de um amplo recinto para acomodar as tropas durantes os ritos em honra à divindade, teriam favorecido sua conversão num macellum, normalmente um pátio descoberto cercado por pórticos e lojas e com uma fonte no centro.

A construção do Fórum de Valente foi a mais importante intervenção imperial na paisagem urbana de Antioquia desde a época de Diocleciano, que no final do século 
III construiu, na ilha formada pelo Orontes, um palácio de amplas proporções, ${ }^{11}$ num contexto em que os imperadores começavam a patrocinar a remodelação de cidades destinadas a abrigar uma corte que se multiplicava no espaço, a exemplo de Tréveris, Milão, Tessalônica, Sírmio, Nicomédia, Antioquia e, naturalmente, Constantinopla. Como argumenta Dey (2015, p. 10), essa intervenção direta do poder imperial na arquitetura da cidade pós-clássica denota uma tentativa de transformá-la num emblema do novo regime, que investia cada vez mais em cerimônias cuja principal finalidade era celebrar a majestade do basileus. Para tanto, fazia-se necessária uma arquitetura adequada aos ritos do poder, uma vez que boa parte dessas cerimônias ocorria a céu aberto, sob atento escrutínio da população. Além disso, o embelezamento das cidades e a realização de obras de infraestrutura constituíam uma maneira eficaz de os soberanos alargarem as suas bases de apoio local, tendo em vista que, antes de ser um súdito do imperador ou um membro do Império, o homem antigo era cidadão da sua cidade, do lugar onde nasceu ou optou por fixar residência, o que o levava a valorizar as intervenções urbanísticas efetuadas pelo poder central, ainda mais se levarmos em consideração o fato de que, no século IV, verifica-se um decréscimo contínuo no volume de recursos à disposição das cúrias municipais para assumirem o ônus da conservação, restauro e ampliação dos edifícios e monumentos cívicos. As construções imperiais, amiúde eternizadas em pedra, promoviam também uma recordação permanente do evergeta, de maneira que sua imagem ficaria unida à própria cidade, configurando assim mais um lugar de memória ao lado de outros tantos que costumam compor a paisagem urbana, saturada de elementos herdados do passado, mesmo que à primeira vista, numa apreensão sinóptica, não nos apercebamos o quanto o padrão visual de uma cidade é marcado pela passagem do tempo e pela coexistência de diversas justaposições e sobreposições temporais, num processo contínuo de mudanças e permanências (BARROS, 2017, p. 55). À luz dessas reflexões é que, em nossa opinião, devemos interpretar a atuação de Valente com o propósito de dotar Antioquia de um novo centro urbano, mais amplo e imponente que o anterior.

O Fórum de Valente é um exemplo de como o imperador foi capaz de criar, para si mesmo, uma imagem positiva que emerge em franca concorrência com as narrativas de Amiano Marcelino, Sócrates, Sozomeno e Teodoreto, autores que enfatizam o estranhamento de Valente com a população de Antioquia em virtude de uma personalidade cruel e intolerante. Se, de fato, Valente se excedeu ao conduzir julgamentos sumários e ao perseguir com violência os dissidentes religiosos, introduzindo assim o aguilhão da stásis em Antioquia, esses acontecimentos não podem, em absoluto, ser tomados como a última palavra acerca do governo do imperador, como a quintessência da sua administração, uma vez que, como vimos, Valente, assim como seu irmão, Valentiniano, se notabilizou como um pródigo construtor. Em Antioquia, a inauguração do fórum representou, sem dúvida, um passo decisivo para reforçar a grandeza da pólis que desde 371 o imperador havia eleito como sua capital, o que é feito, importa mencionar, sem qualquer traço de fundamentalismo religioso, mas antes buscando-se um compromisso com a tradição. Na construção do novo fórum, Valente não destrói pura e simplesmente os edifícios antigos, mantendo a êxedra do Kaisarion, o Kommodion, o Horologion, o Plethrion e o Xystós. Apenas 
o Templo de Ares, ao que parece, é convertido num macellum, mas é bem possível que o edifício já estivesse em desuso antes mesmo da reforma. O mais relevante para um imperador qualificado como intolerante em matéria de religião é a inexistência, no fórum, de qualquer igreja ou santuário cristão, o que exprime a preocupação de Valente em preservá-lo como um espaço cívico constituído por monumentos ad usum publicum cujos frequentadores possuíam crenças distintas. Por essa razão, a hipótese formulada por Gunnar Brands (2018, p. 22) segundo a qual a criação do Fórum de Valente teria favorecido a cristianização da cidade necessita, sem dúvida, de reparos. Evidência suplementar de que, para além da perseguição aos nicenos de Melécio, Valente não adotou, em Antioquia, nenhuma medida mais severa do ponto de vista religioso nos é fornecida por Teodoreto de Ciro (Hist. Eccl. IV, XXI), que acusa o imperador de ter permitido o livre trânsito de judeus e pagãos pelas ruas da cidade, de maneira que os devotos de Deméter e de Dioniso, outrora confinados a locais menos visíveis, foram autorizados a praticar seus ritos à vista de todos, cruzando o fórum em desabalada carreira, o que nos permite concluir que a reforma realizada pelo imperador não teve por objetivo impedir ou dificultar o acesso dos adeptos de outros credos aos espaços coletivos da cidade, cuja principal característica era a sua capacidade de congregar os habitantes e não de os segregar, o que se encontra em sintonia com a diversidade religiosa própria de Antioquia. Nesse sentido, até onde sabemos, a construção do fórum não gerou nenhum estranhamento entre Valente e os antioquenos, muito pelo contrário.

\section{Considerações finais}

O Fórum de Valente constitui um notável exemplo de como os imperadores do século IV lidaram com o fato de Roma ter perdido, na época tardia, a sua condição de capital do orbis romanorum, o que os forçava a se instalar em cidades que, não tendo sido outrora sedes do poder imperial, passavam a se beneficiar da presença da corte, o que não poderia deixar de impactar o ambiente urbano e a própria representação que os citadinos faziam da sua pólis, pois a imagem que as pessoas elaboram das cidades é diretamente condicionada pela figurabilidade das formas arquitetônicas, ${ }^{12}$ ou seja, pela capacidade de um elemento da paisagem construída suscitar, no observador, uma vívida emoção, conservando-se assim na memória como uma síntese do ethos urbano (LYNCH, 2010, p. 31), a exemplo do Cristo Redentor, da Estátua da Liberdade, do Coliseu e de tantos outros monumentos ao redor do mundo. Em Antioquia, é um processo dessa natureza que parece ocorrer mediante a criação do Fórum de Valente, que em dimensão rivalizava com os fóruns de Roma e Constantinopla. Situado nas proximidades do Nymphaeum e na interseção dos eixos da avenida das colunatas, defronte à ilha do Orontes e à ágora de Epifânia, o Fórum de Valente se destacava como o ponto focal da ásty, desempenhando um papel político de primeira grandeza, uma vez que, como observa Lavan (2006, p. 207), nas cidades antigas a opção por construir uma ampla praça a céu aberto se devia, na maioria dos casos, à capacidade de um espaço como esse abrigar amplos contingentes da população, que se aglomerava para acompanhar com vívido interesse os atos solenes da monarquia, o que explica o cuidado com a construção e restauro desses recintos na África do 
Norte e nas províncias orientais até pelo menos o século V. Além disso, as basílicas instaladas nas praças da cidade costumavam ser palco dos julgamentos presididos pelos governadores de província, o que reforçava a importância do fórum como um local apropriado ao exercício do poder imperial. Por todos esses motivos, é possível afirmar que o Fórum de Valente foi um monumento capaz de conferir a Antioquia um esplendor à altura das outras capitais, contribuindo assim para forjar a identidade da própria população. Segundo o anônimo autor da Expositio totius mundi et gentium (32), Antioquia era uma cidade que contava com toda sorte de facilidades pelo fato de "ser lá que o imperador mantém sua residência, tornando-se tudo necessário por sua presença". Na perpetuação de uma imagem de Antioquia como a que vemos aqui descrita, o papel de Valente foi decerto fundamental, o que nos obriga a reconsiderar os testemunhos de Amiano Marcelino e dos historiadores eclesiásticos sobre os desacertos que teriam caracterizado o governo de um imperador que, de resto, é um dos mais maltratados pela historiografia.

\section{Referências}

ALFÖLDY, A. A conflict of the ideas in the Later Roman Empire: the clash between the Senate and Valentinian I. Oxford: Clarendon Press, 1952.

BABUT, C. E. Recherches sur la garde impériale et sur le corps d'officiers de l'armée romaine aux IV et V siècles. Revue Historique, n. 114, p. 225-260, 1913.

BARROS, J. A. História, espaço, Geografia. Petrópolis: Vozes, 2017.

BERARDINO, A. Dicionário patrístico e de Antigüidades cristãs. Petrópolis: Vozes, 2002.

BRANDS, G. Preservation, historicization, change: Antioch A. D. 350-450. In: BERGJAN, S. P.; ELM, S. (ed.). Antioch II. Tübingen: Mohr Siebeck, 2018, p. 13-33.

CRAWFORD, P. Constantius II: usurpers, eunuchs and the Antichrist. Barnsley: Pen \& Sword, 2016.

CROSS, F. L.; LIVINGSTONE, E. A. The Oxford dictionary of the Christian Church. Oxford: Oxford University Press, 2005.

CURRAN, J. From Jovian to Theodosius. In: CAMERON, A.; GARNSEY, P. (ed.). The Cambridge Ancient History. Cambridge: Cambridge University Press, 2008, p. 78-110. v. XIII.

DEY, H. W. The afterlife of the Roman city: architecture and ceremony in Late Antiquity and the Early Middle Ages. Cambridge: Cambridge University Press, 2015.

DOWNEY, G. A history of Antioch in Syria. Princeton: Princeton University Press, 1961.

HUGHES, I. Imperial brothers: Valentinian, Valens and the disaster at Adrianople. Barnsley: Pen \& Sword, 2013. 
FESTUGIÈRE, A. J. Antioche paiënne et chrétienne: Libanius, John Chrysostom and les moines de Syrie. Paris: de Boccard, 1959.

JONES, A. H. M. The Later Roman Empire (284-602). Oxford: Basil Blackwell, 1964.

KELLY, J. N. D. Golden Mouth: the story of John Chrysostom. Ithaca: Cornell University Press, 1995.

KELLY, G. Ammianus, Valens, and Antioch. In: BERGJAN, S. P.; ELM, S. (ed.). Antioch II. Tübingen: Mohr Siebeck, 2018, p. 137-162.

LAVAN, L. Fora and agorai in Mediterranean cities during the $4^{\text {th }}$ and the $5^{\text {th }}$ C. A.D. In: BOWDEN, W.; GUTTERIDGE, A.; MACHADO, C. (ed.). Social and political life in Late Antiquity. Leiden: Brill, 2006, p. 195-249.

LENSKY, N. Valens and the monks: cudgeling and conscription as a means of social control. Dumbarton Oak Papers, v. 58, p. 93-117, 2004.

LENSKY, N. Failure of Empire: Valens and the Roman State in the fourth century A. D. Berkeley: University of California Press, 2002.

LYNCH, K. L'immagine della città. Venezia: Marsilio, 2010.

PETIT, P. Libanius et la vie municipal a Antioche au IVe siècle après J.-C. Paris: Geuthner, 1955.

POCCARDI, G. Antioche de Syrie. Pour un nouveau plan urbain de l'île de l'Oronte (Ville Neuve) du Ille au Ve siècle. Mélanges de l'École Française de Rome, t. 106, n. 2, p. 993-1023, 1994.

ROBERTSON, D. S. Arquitetura grega e romana. São Paulo: Martins Fontes, 1997.

SALIOU, C. Le palais impérial d'Antioche et son contexte à l'époque de Julien. Antiquité Tardive, n. 17, p. 235-250, 2009.

SILVA, G. V. A escalada dos imperadores proscritos: Estado, conflito e usurpação na Antiguidade Tardia (285-395). Vitória: GM Editora, 2018.

SILVA, G. V.; MENDES, N. M. Diocleciano e Constantino: a construção do Dominato. In: SILVA, G. V.; MENDES, N. M. (org.). Repensando o Império Romano. Rio de Janeiro: Mauad, 2006, p. 193-221.

SILVA, G. V. Reis, santos e feiticeiros: Constâncio II e os fundamentos místicos da basileia (337-361). Vitória: Edufes, 2003.

SNEE, R. Valen's recall of the Nicene exiles and anti-Arian propaganda. Greek, Roman, and Byzantine Studies, n. 26, p. 395-419, 1985.

SOLER, E. Le sacré et le salut à Antioche au IVe siècle après J.-C.: pratiques festives et comportements religieux dans le processus de christianisation de la cité. Beyrouth: Institut Français du Proche-Orient, 2006. 


\section{Fontes}

AMMIANUS MARCELLINUS. History: books 27-31. Translated by John C. Rolfe. Cambridge: Harvard University Press, 1939.

EXPOSITIO TOTIUS MUNDI ET GENTIUM. Introduction, texte critique, traduction, notes et commentaires par Jean Rougé. Paris: Du Cerf, 1966.

JOHN MALALAS. Chronicle. Translated by Elizabeth Jeffreys, Michael Jeffreys and Roger Scott. Leiden: Brill, 2017.

LIBANIUS. The Antiochikos: in praise of Antioch. In: Antioch as a centre of Hellenic culture. Translated with an introduction by A. F. Norman. Liverpool: Liverpool University Press, 2000, p. 4-65.

PHARR, C.; DAVIDSON, T. S. (Ed.). The Theodosian Code and novels, and Sirmondian Constitutions. Princeton: Princeton University Press, 1952.

SOCRATES. The Ecclesiastical History. In: SCHAFF, P.; WACE, H. (Ed.). Nicene and post-Nicene fathers. Text translated by A. C. Zenos. Peabody: Hendrickson, 2004, p. 1-178. v. 2.

SOZOMENUS. The Ecclesiastical History. In: SCHAFF, P.; WACE, H. (Ed.). Nicene and post-Nicene fathers. Text translated by Chester D. Hartranfty. Peabody: Hendrickson, 2004, p. 181-427. v. 2.

TEMISTIO. Discorsi. A cura di Riccardo Maisano. Torino: Utet, 1995.

TEODORETO DE CIRO. Historias de los monjes de Siria. Introducción, traducción y notas de Ramón Teja. Madrid: Trotta, 2008.

THEODORET. The Ecclesiastical History. In: SCHAFF, P.; WACE, H. (Ed.). Nicene and post-Nicene fathers. Text translated by Blomfield Jackson. Peabody: Hendrickson, 2004, p. 33-159. v. 3.

\section{Notas}

1 Sobre o sentido e o alcance da obra reformadora de Diocleciano, mais tarde aprofundada por Constantino, consultar Silva e Mendes (2006).

2 Nos referimos aqui aos imperadores ditos "legítimos", ou seja, àqueles que faziam parte da linhagem imperial, assumindo a púrpura na condição de sucessores, ou que foram reconhecidos pelas tropas e pela aristocracia como soberanos com plenos direitos de governar. Se passarmos ao caso dos "imperadores proscritos", ou seja, dos usurpadores, a lista de soberanos efêmeros e mal conhecidos certamente será muito maior. Para mais informações sobre o assunto, consultar Silva (2018).

${ }^{3}$ Graciano, pai de Valentiniano e Valente, foi um distinto comandante militar sob o governo de Constantino e de seus filhos, tendo ocupado a posição de comes Africae no decorrer da década de 320. Por volta de 338, por decisão de Constante, Graciano foi nomeado comes Britaniae. Por volta de 351, aposentou-se da carreira militar e passou a dedicar seu tempo à administração da propriedade que havia adquirido na Panônia, a mesma entregue a Valente para supervisionar. 
É possível que Graciano estivesse ainda vivo à época da proclamação de seus filhos como Augustos, pois a estátua em sua memória dedicada pelo vicário da África data de 367, sugerindo assim uma morte recente (LENSKY, 2002, p. 47).

${ }_{4}$ Desde o episódio da enfermidade dos irmãos logo no início do governo, em 364, Valentiniano sempre se mostrou bastante atento às denúncias de veneficium, o que levou à execução de muitos acusados de tal crime sob seu governo. No Ocidente, a perseguição aos adivinhos e feiticeiros permaneceu circunscrita aos membros da ordem senatorial, ao passo que, no Oriente, foram implicados homens de diversas categorias sociais. O conflito se inicia em 369 , quando Maximino, então prefeito da anona, envia um comunicado à casa imperial declarando que, em Roma, o emprego das artes mágicas pela aristocracia era uma prática rotineira. Alarmado, Valentiniano decide instaurar uma comissão para apurar o caso. Como resultado, inúmeros aristocratas foram detidos, torturados e condenados. Ao mesmo tempo, verifica-se um endurecimento da legislação. Em 12 de dezembro de 370, numa lei endereçada ao prefeito do pretório do Oriente (C. Th., 9, 16 , 5), Valentiniano e Valente determinam o fim do ensino da astrologia, uma das modalidades divinatórias mais comuns no Império. Tanto os astrólogos quanto os consulentes estariam sujeitos à pena capital, não importando se houvessem consultado os astros em público ou privadamente. Para maiores detalhes sobre os processos acusatórios levados a cabo por Valentiniano contra membros da elite senatorial romana, consultar o hoje clássico trabalho de Alföldy (1952).

5 O sabelianismo era a doutrina ensinada por Sabélio, condenado, em 220, por iniciativa de Calisto, bispo de Roma, devido a suas ideias de tendência monarquiana acerca da encarnação de Cristo. Para Sabélio e seus seguidores, haveria apenas um único Deus, que se manifestaria como Pai, no Antigo Testamento; como Filho, no episódio da Encarnação; e como Espírito Santo após Pentecostes. Contrariamente à doutrina das três hipóstases ou pessoas de Deus, da qual Orígenes era um dos principais defensores, os sabelianos sustentavam que Pai, Filho e Espírito Santo constituíam uma única hipóstase (BERARDINO, 2002, p. 1238).

6 Os homeousianos são também conhecidos como semi-arianos, na medida em que sua teologia busca uma solução de compromisso entre a doutrina nicena e a anomeana. Sua designação provém de homoiousios, termo atestado pela primeira vez na fórmula do Concílio de Sírmio, reunido em 357. Os homeousianos acreditavam na existência de três hipóstases da Trindade, cada uma delas possuindo uma ousia (substância) própria, que não se confundiria com as demais, embora compartilhassem a mesma essência. Já os nicenos sustentavam que o Filho possuía a mesma substância do Pai, sendo, portanto, homoousios. Quanto aos anomeanos ou anomeus, ou seja, aos arianos radicais, recusavam-se a aceitar qualquer similitude entre Pai e Filho, motivo pelo qual este último era declarado anomoios, ou seja, diferente do Pai pelo fato de ter sido gerado e, portanto, não compartilhar a eternidade divina. O principal expoente dos anomeus foi Eunômio de Cízico (BERARDINO, 2002, p. 106 e 691).

${ }^{7}$ Não bastasse a interferência do poder imperial, em 375 ou 376 a situação se torna ainda mais confusa para os cristãos de Antioquia devido à ordenação de Vital como bispo por Apolinário de Laodiceia, que em 373 se encontrava ensinando na cidade. Desse modo, um pouco antes da morte de Valente, em 378, quatro bispos disputavam o controle da sé de Antioquia: Euzoio, Melécio, Paulino e Vital. Mais tarde, quando do retorno de Melécio, Vital foi rapidamente neutralizado (DOWNEY, 1961, p. 412).

8 De acordo com Lensky (2002, p. 252), a manutenção de Paulino em Antioquia poderia ser interpretada como um sinal de boa vontade de Valente para com os nicenos, uma vez que o imperador estaria menos interessado em suprimir os partidários do homoousios do que em solucionar o cisma entre Paulino e Melécio. Não concordamos, em absoluto, com a opinião do autor, pois a superação do dissenso entre os nicenos resultaria, ao fim e ao cabo, na formação de uma comunidade forte o suficiente para confrontar os arianos, liderados por Euzoio, o que de 
modo algum seria compatível com a política religiosa implementada pelo imperador no Oriente, configurando antes um erro crasso de estratégia.

9 No decorrer da Controvérsia Ariana, os monges se alinharam, na maioria dos casos, com os defensores do credo de Niceia, o que os tornava particularmente refratários ao governo de Valente. O imperador, por sua vez, não demonstrava qualquer boa vontade para com os monges, a quem acusava de indolência por se recusarem a servir no exército, comportamento que drenava a mão de obra disponível. Com o propósito de solucionar o problema, Valente promulga, em 375, uma lei determinando que os monges deveriam servir como milites sob pena de serem fustigados com bastões até a morte. Para mais informações, consultar Lensky (2004).

${ }_{10} \mathrm{~A}$ êxedra era um recesso aberto em formato semicircular ou retangular destinado a reuniões, uma vez que costumava comportar bancos de pedra à guisa de arquibancadas. As êxedras poderiam ser instaladas na entrada de alguns edifícios, como as basílicas, de modo a valorizar a construção e torná-la mais atraente ao público (ROBERTSON, 1997, p. 455).

11 Informações suplementares sobre a construção do palácio do Orontes por Diocleciano, o que deu ensejo à formação de um distrito denominado "Cidade Nova", podem ser encontradas em Saliou (2009) e Poccardi (1994).

12 Embora, no original, Lynch (2010) empregue o neologismo imageability, optamos por utilizar aqui, por razões de eufonia, o vocábulo figurabilidade, tradução do italiano figurabilitá, tal como proposto na versão que consultamos, publicada em Veneza.

Gilvan Ventura da SILVA. Professor Titular de História Antiga da Universidade Federal do Espírito Santo (Ufes). Doutor em História pela Universidade de São Paulo, bolsista produtividade 1-C do CNPq e pesquisador do Laboratório de Estudos sobre o Império Romano (Leir). No momento, executa o projeto Migração, movimento e desordem na cidade pós-clássica: Antioquia e os efeitos da dinâmica populacional (356-397 d.C.).

\section{Editores}

Paulo Cesar Gonçalves e Valéria dos Santos Guimarães
Submissão: 08/03/2020

Aceite: 06/04/2020 